Check for updates

Cite this: RSC Adv., 2019, 9, 7479

\title{
An efficient Nozaki-Hiyama allenylation promoted by the acid derived MIL-101 MOF $\uparrow$
}

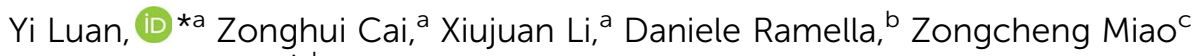 \\ and Wenyu Wang*d
}

A concise synthesis of the sulfonic acid-containing MIL-101 MOF catalyst was reported using commercially available materials. A series of characterization of as-synthesized MIL-101-SO ${ }_{3} \mathrm{H}$ including SEM, XRD, FTIR, BET and TGA was also demonstrated. Using MIL-101- $\mathrm{SO}_{3} \mathrm{H}$ as a catalyst, an efficient Nozaki-Hiyama allenylation reaction was achieved to generate various polyfunctionalized $\alpha$-allenic alcohols in high yield and good selectivity. Taking advantage of the high acidity of the MIL-101- $\mathrm{SO}_{3} \mathrm{H}$ MOF structure, such transformations were also achieved under mild reaction conditions and short reaction times. Based on our observed evidence during this study, a mechanism was proposed involving a substrate activation $/ \gamma$ nucleophilic addition reaction sequence. In addition, the $\mathrm{MIL}-101-\mathrm{SO}_{3} \mathrm{H}$ catalyst can be recycled ten times during the Nozaki-Hiyama allenylation reaction without compromising the yield and selectivity.

Received 22nd November 2018 Accepted 9th February 2019

DOI: $10.1039 / \mathrm{c} 8 \mathrm{ra09600 \textrm {g }}$

rsc.li/rsc-advances structure, they have been used as the efficient solid catalysts for several catalytic transformations. ${ }^{\mathbf{1 0}}$ Among all the reported examples, a stable and recyclable MOF structure bearing sulfonic acid functionality can serve as a low $\mathrm{p} K_{\mathrm{a}}$ catalytic material, ${ }^{11}$ and we eventually choose to use a chemically stable and previously described MIL-101-SO $\mathrm{S}_{3} \mathrm{H}$ MOF in our catalytic reaction development study. ${ }^{12}$ Due to its chemical and physical stabilities, MIL-101- $\mathrm{SO}_{3} \mathrm{H}$ has been utilized as an efficient catalyst for several organic reactions. ${ }^{13}$

Herein, we reported a highly efficient Nozaki-Hiyama allenylation reaction catalyzed by MIL-101- $\mathrm{SO}_{3} \mathrm{H}$ MOF using propargyl boronates, which provided rapid access to the $\alpha$-allenic alcohol products. This newly synthesized MIL-101-SO $\mathrm{SO}_{3} \mathrm{H}$ catalyst bearing aromatic sulfonic acid groups was obtained using commercially available monosodium 2-sulfoterephthalate. A broad scope of propargyl boronates and aldehydes were tested to be tolerable under the optimal reaction conditions with high catalytic reactivities. Furthermore, the as-synthesized MIL-101$\mathrm{SO}_{3} \mathrm{H}$ catalyst can be readily filtered and separated from the allenylation reaction mixture. Recycling the MIL-101- $\mathrm{SO}_{3} \mathrm{H}$ up to ten times doesn't compromise yield or selectivity of the benzaldehyde allenylation.

\section{Results and discussion}

Beijing, 30 Xueyuan Road, Haidian District, Beijing 100083, P. R. China. E-mail: yiluan@ustb.edu.cn

${ }^{b}$ Department of Chemistry, Temple University-Beury Hall, 1901, N. 13th Street, Philadelphia, PA 19122, USA

'Key Laboratory of Organic Polymer Photoelectric Materials, School of Science, Xijing University, Xi'an, 710123, China

${ }^{d}$ Broad Institute, 415 Main Street, Cambridge, Massachusetts 02142, USA

$\dagger$ Electronic supplementary information (ESI) available. See DOI: $10.1039 / \mathrm{c} 8 \mathrm{ra09600g}$
MIL-101- $\mathrm{SO}_{3} \mathrm{H}$ can be readily synthesized and purified according to the reported hydrothermal methods as a crystalline powder. ${ }^{14}$ It is isostructural to MIL-101 (Fig. 1), and thus has the same pore structures. The SEM images of MIL-101- $\mathrm{SO}_{3} \mathrm{H}$ showed (Fig. 1) the rectangular crystals of $\mathrm{MIL}-101-\mathrm{SO}_{3} \mathrm{H}$ are evenly distributed with a size of $200 \mathrm{~nm}$. 

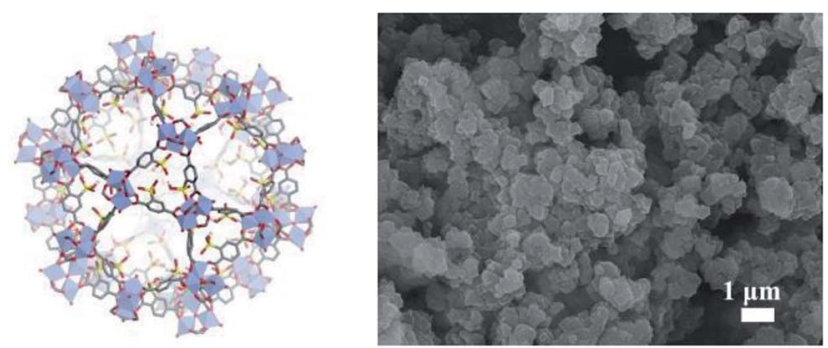

Fig. 1 The detailed structure of MIL-101-SO ${ }_{3} \mathrm{H}$ and its SEM image.

Subsequently, powder X-ray diffraction (PXRD) measurements were conducted (Fig. 2) and showed good agreement with literature values. ${ }^{15}$ In addition, the obtained XRD data of MIL101- $\mathrm{SO}_{3} \mathrm{H}$ demonstrated high similarity to the XRD patterns of the MIL-101, which also indicated our successful preparation of the MIL-101-SO $\mathrm{S}_{3} \mathrm{H}$ MOF.

The specific surface areas of the products were then analyzed by $\mathrm{N}_{2}$ adsorption-desorption measurements at $77 \mathrm{~K}$. As shown in Fig. 3, the trace of the MIL-101- $\mathrm{SO}_{3} \mathrm{H}$ showed a type-I isotherm. $\mathrm{N}_{2}$ gas sorption isotherms reveal a BrunauerEmmett-Teller (BET) surface area of $1243 \mathrm{~m}^{2} \mathrm{~g}^{-1}$.

Additionally, the thermal structural stabilities of MIL-101$\mathrm{SO}_{3} \mathrm{H}$ were examined by thermal gravimetric analysis (TGA). A weight loss at about $300{ }^{\circ} \mathrm{C}$ was observed during the TGA measurement, ${ }^{\mathbf{1 6}}$ which indicated high thermal stability of the acid derived MIL-101- $\mathrm{SO}_{3} \mathrm{H}$ sample, which should provide reliable stability during the catalytic reaction temperature range (Fig. 4).

With the MOF catalyst in hand, we started our catalytic Nozaki-Hiyama allenylation reaction studies. Several reaction factors such as nature of the catalyst and solvent, were tested in order to reveal the optimal reaction condition (Table 1). First, a control experiment was performed to study the background rate of the allenylation reaction of propargyl boronate 1a. As expected, no conversion was observed for propargyl boronate 1a in the absence of catalyst or using biphenol as the catalyst (Table 1, entries 1-2) suggesting that a low $\mathrm{p} K_{\mathrm{a}}$ acid is indeed

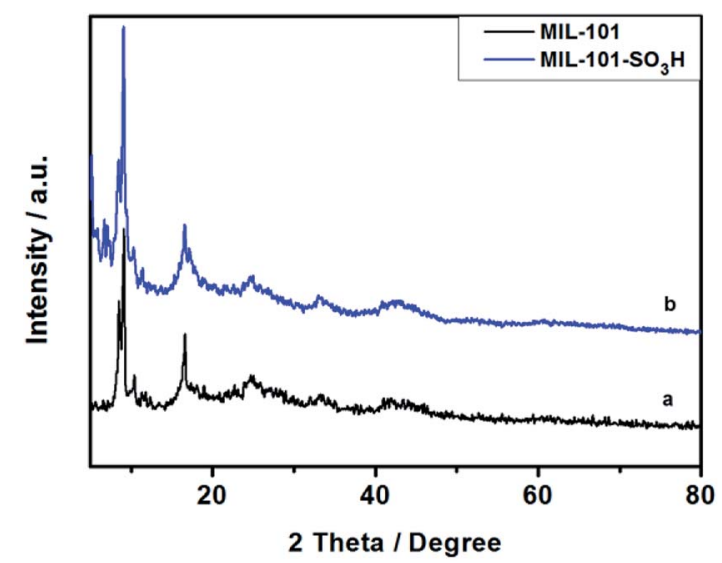

Fig. 2 Powder XRD patterns of (a) MIL-101 and (b) MIL-101-SO ${ }_{3} \mathrm{H}$.

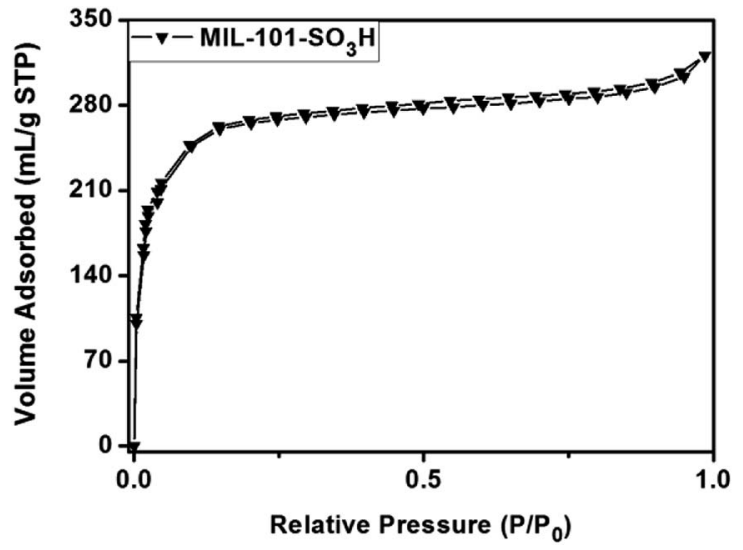

Fig. $3 \mathrm{~N}_{2}$ adsorption-desorption isotherm of $\mathrm{MIL}-101-\mathrm{SO}_{3} \mathrm{H}$.

necessary for the reaction to occur. Subsequently, $\mathrm{HCl}$ showed modest yield at $1 \mathrm{~mol} \%$ catalytic loading and the reaction was slow due to the low catalyst loading and undesired $\alpha$-addition byproduct 4a (Table 1, entry 3) was also observed. $p$-TsOH provided satisfying yield and selectivity at $1 \mathrm{~mol} \%$ catalyst loading, despite the fact it is not recyclable and being corrosive to several equipments (Table 1, entry 4). As expected, MIL-101 bearing no acidic functional group provided only traces of product at $23{ }^{\circ} \mathrm{C}$ in $\mathrm{CH}_{2} \mathrm{Cl}_{2}$ solvent (Table 1, entry 5). We expect metal-organic framework material bearing $-\mathrm{SO}_{3} \mathrm{H}$ can provide the high reaction efficiency and recyclable nature at the same time. Our previously reported UiO-66- $\mathrm{RSO}_{3} \mathrm{H}$ indeed provided an increase for the yield. ${ }^{17}$ However, alkyl sulfonic acid functional group inside the $\mathrm{UiO}-66-\mathrm{RSO}_{3} \mathrm{H}$ catalyst was not acidic enough to provide the quantitative conversion (Table 1, entry 6). In contrast, 1 mol\% MIL-101- $\mathrm{SO}_{3} \mathrm{H}$ showed almost quantitative conversion and over $99 \%$ selectivity for the allenylation $\mathbf{1 a} .^{\mathbf{1 7}}$ The greatly enhanced acidity could efficiently allow the rearrangement of boronate for $\gamma$-nucleophilic addition to aldehyde to provide the desired $\alpha$-allenic alcohol $2 \mathbf{a}$ in excellent yield (Table 1, entry 7). Toluene gave almost comparable yield for the allenylation reaction (Table 1 , entry 8 ). Polar nonprotic/protic solvents, such as THF and ethanol, gave decent yield of the

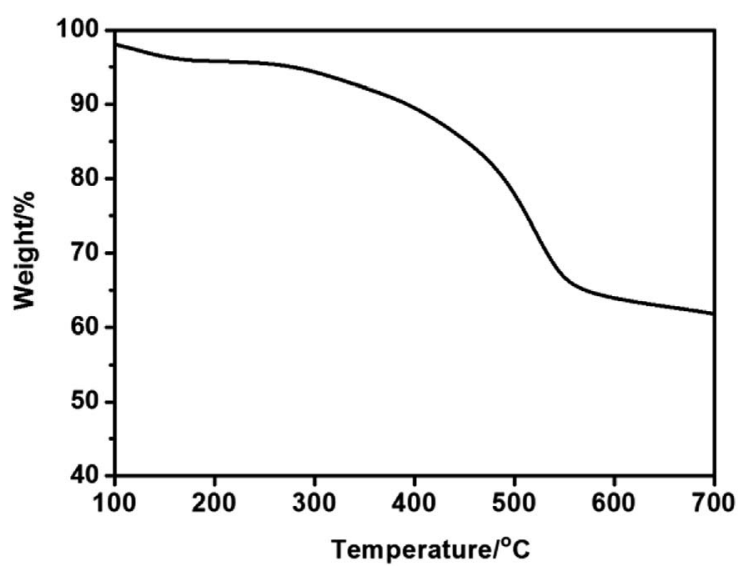

Fig. 4 TGA of MIL-101- $\mathrm{SO}_{3} \mathrm{H}$. 
Table 1 Reaction condition optimization for allenylation reaction ${ }^{a}$

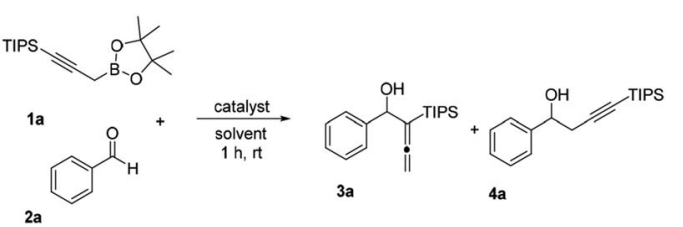

\begin{tabular}{|c|c|c|c|c|}
\hline Entry & Catalyst & Solvent & Yield of $\mathbf{3 a}$ & Selectivity \\
\hline 1 & - & $\mathrm{CH}_{2} \mathrm{Cl}_{2}$ & $<5 \%$ & N.A. \\
\hline 2 & Biphenol & $\mathrm{CH}_{2} \mathrm{Cl}_{2}$ & $<5 \%$ & N.A. \\
\hline 3 & $\mathrm{HCl}$ & $\mathrm{CH}_{2} \mathrm{Cl}_{2}$ & $53 \%$ & $71 \%$ \\
\hline 4 & $p$-TsOH & $\mathrm{CH}_{2} \mathrm{Cl}_{2}$ & $91 \%$ & $99 \%$ \\
\hline 5 & MIL-101 & $\mathrm{CH}_{2} \mathrm{Cl}_{2}$ & $<5 \%$ & N.A. \\
\hline 6 & UiO-66- $\mathrm{RSO}_{3} \mathrm{H}$ & $\mathrm{CH}_{2} \mathrm{Cl}_{2}$ & $77 \%$ & $96 \%$ \\
\hline 7 & MIL-101-SO ${ }_{3} \mathrm{H}$ & $\mathrm{CH}_{2} \mathrm{Cl}_{2}$ & $99 \%$ & $99 \%$ \\
\hline 8 & MIL-101-SO ${ }_{3} \mathrm{H}$ & $\mathrm{PhCH}_{3}$ & $98 \%$ & $99 \%$ \\
\hline 9 & MIL-101-SO ${ }_{3} \mathrm{H}$ & THF & $68 \%$ & $99 \%$ \\
\hline 10 & MIL-101-SO ${ }_{3} \mathrm{H}$ & EtOH & $44 \%$ & $99 \%$ \\
\hline 11 & MIL-101- $\mathrm{SO}_{3} \mathrm{H}$ & DMF & $23 \%$ & $99 \%$ \\
\hline
\end{tabular}

${ }^{a}$ Reaction condition: 1 mol\% catalyst, TIPS propargyl boronate 1a and benzaldehyde $2 \mathrm{a}$ were stirred in the solvent $(0.2 \mathrm{M})$ for $1 \mathrm{~h}$ at room temperature.

desired allenylation product with diminished yields (Table 1 , entries 9-10). Mildly basic solvent, DMF was not suitable for the acidic heterogeneous MIL-101- $\mathrm{SO}_{3} \mathrm{H}$ promoted allenylation reaction (Table 1, entry 11). Further solvent evaluation indicated that dichloromethane is the optimal reaction solvent for further allenylation reaction studies (Table 1, entries 7-11). Optimization of catalyst structure demonstrated that MIL-101- $\mathrm{SO}_{3} \mathrm{H}$ can efficiently catalyze the allenylation reaction using propargyl boronates and aldehyde as the starting material.

With an optimal catalyst and reaction condition identified, the scope of propargyl boronate reaction partners were next investigated. Simple TIPS-protected boronate $\mathbf{1 a}$ and benzaldehyde 2a resulted in quantitative formation of 3a without any undesired propargyl $\alpha$-addition byproduct (Table 2, entry 1 ). Phenyl substituted propargyl boronate $\mathbf{1 b}$ also tolerated this chemistry, which gave allenic alcohol $\mathbf{3 b}$ in $95 \%$ yield. The 1,1disubstituted vinyl moiety on $\mathbf{1 c}$ is known to undergo protonation to generate a stabilized tertiary carbocation which potentially provide us a diminished yield of the desired allenylation product. Gratifyingly, the complex vinylpropargyl borate $\mathbf{1 c}$ also gave desired $\mathbf{3 c}$ in excellent yield (Table 2, entry 3) under identical reaction condition, which illustrated the versatility of MIL-101- $\mathrm{SO}_{3} \mathrm{H}$ as a catalyst in this reaction. Consistently, acid labile substrate 1d also provided desired product 3d in great yield without losing TBS group (Table 2, entry 4$)$.

We next examined MIL-101- $\mathrm{SO}_{3} \mathrm{H}$ catalyst in allenylation of a wide variety of aldehydes (Table 3). Electronic rich and deficient benzaldehydes as well as polyaromatic benzaldehyde (2e2h) were all shown to be tolerant for such transformation, as well as a heterocyclic aldehyde such as furfurals ( $2 \mathbf{i}$ and $2 \mathbf{j}$ ). The
Table 2 Nucleophile (boronate) variations for allenylation reaction ${ }^{a}$

a

$\alpha, \beta$-unsaturated aldehyde $2 \mathbf{k}$ was also tested and only the desired addition product was observed in $95 \%$ yield, although boronates are known to undergo 1,4-addition into enones. More challenging aliphatic aldehydes (2l-2n, 2p) also provide

Table 3 Electrophile (aldehyde) variations for allenylation reaction ${ }^{a}$

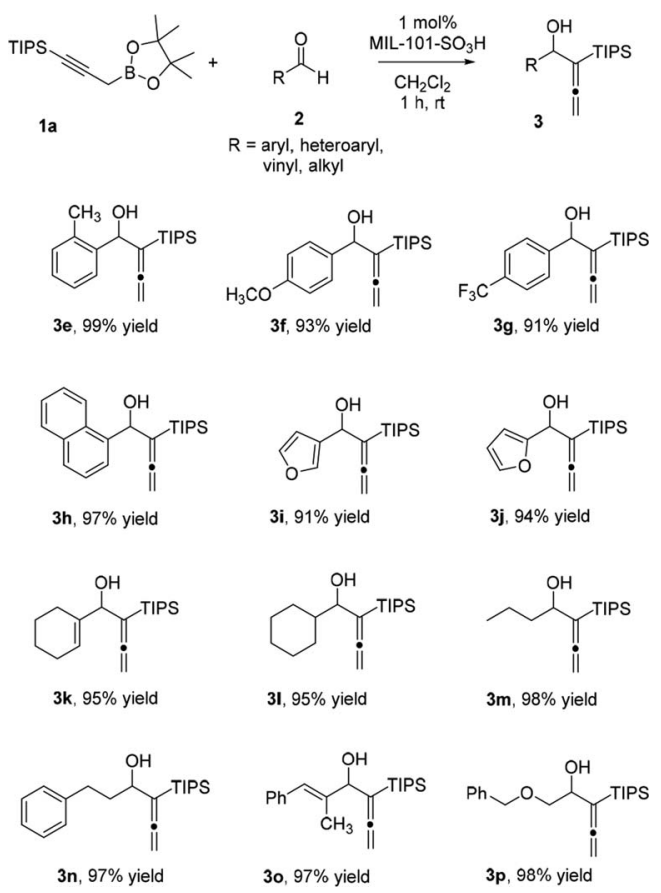

${ }^{a}$ Reaction condition: 1 mol\% MIL-101-SO ${ }_{3} \mathrm{H}$, propargyl boronate 1 and benzaldehyde $2 \mathrm{a}$ were stirred in $\mathrm{CH}_{2} \mathrm{Cl}_{2}$ for $1 \mathrm{~h}$ time at room temperature. 
excellent yields and selectivity. Furthermore, alkene aldehydes $(2 \mathbf{k}, 2 \mathbf{2})$ were shown to be well tolerant in our catalytic system to provide corresponding allenic alcohols in more than 95\% yields.

A detailed reaction mechanism has been proposed. First, the Brønsted acidic site on MIL-101- $\mathrm{SO}_{3} \mathrm{H}$ catalyst would activate the aldehyde substrate by protonation, and simultaneously, the generated sulfonate anion on the backbone of the MOF catalyst could further activate the boronate species to form intermediate A (Scheme 1). Therefore, by using our heterogeneous catalyst MIL-101- $\mathrm{SO}_{3} \mathrm{H}$ formation of the key zwitterionic intermediate $\mathbf{A}$ could introduce a better reactant approximation for the ideal reactivity to occur whereas using traditional acid, such as $\mathrm{HCl}$, would bring less control of the desired reactivity which lead to formation of the undesired propargyl alcohols ( $c f$. Table 1). The well-defined porous structure of the catalyst will facilitate this double activation of both reactant and trigger the desired $\gamma$ nucleophilic addition from boronate to the aldehyde.

However, if such double activation did not work properly, the undesried $\alpha$-nucleophilic addition could also happen to give the propargyl byproduct. Subsequently, the catalyst could be regenerated by hydrolysis of borate intermediate $\mathbf{B}$.

Additionally, we tested recyclability of the acidic MIL-101$\mathrm{SO}_{3} \mathrm{H}$ catalyst and showed that it can be recycled up to ten times without compromising the yield and selectivity of the allenylation reaction of aldehyde 1a. The recyclability of the MIL-101$\mathrm{SO}_{3} \mathrm{H}$ catalyst was evaluated using TIPS-propargyl boronate 1a in $2 \mathrm{~mL}$ of $\mathrm{CH}_{2} \mathrm{Cl}_{2}$ at room temperature. As for MIL-101- $\mathrm{SO}_{3} \mathrm{H}$, the yield of desired 3a remained $98 \%$ after usage of the same recycled catalyst with 10 batches of fresh reagent (Fig. 5).

A hot filtration test was also performed for the MIL-101- $\mathrm{SO}_{3} \mathrm{H}$ catalyzed allenylation reaction. After 20 minutes of reaction, the solid MIL-101- $\mathrm{SO}_{3} \mathrm{H}$ catalyst was filtered off and at this point, the allenylation of aldehyde 1a did not further proceed, which further suggested no acid leaching into the reaction solution (Fig. 6). Meanwhile SEM images and X-ray powder diffraction spectrum of the MIL-101-SO $\mathrm{S}_{3} \mathrm{H}$ catalyst were also recorded after ten allenylation reaction cycles. These data were found to be identical to those of the freshly prepared catalyst (Fig. S1 and

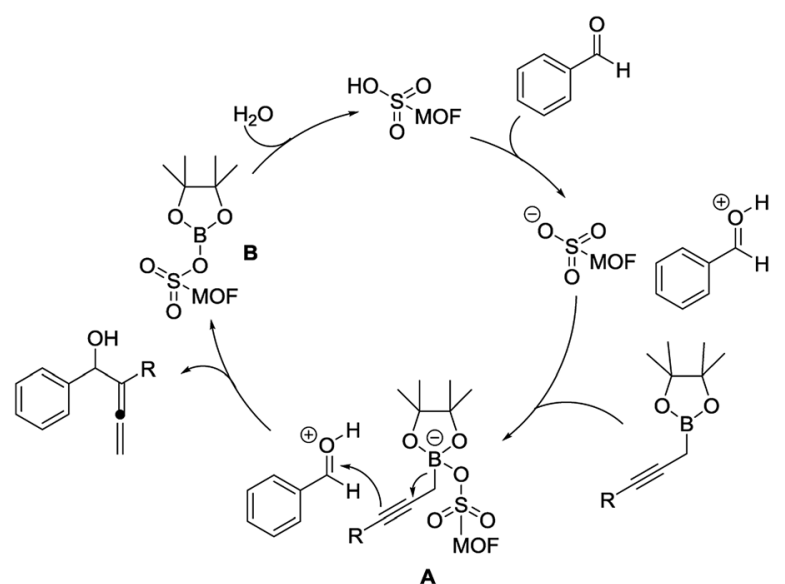

Scheme 1 Proposed reaction mechanism.

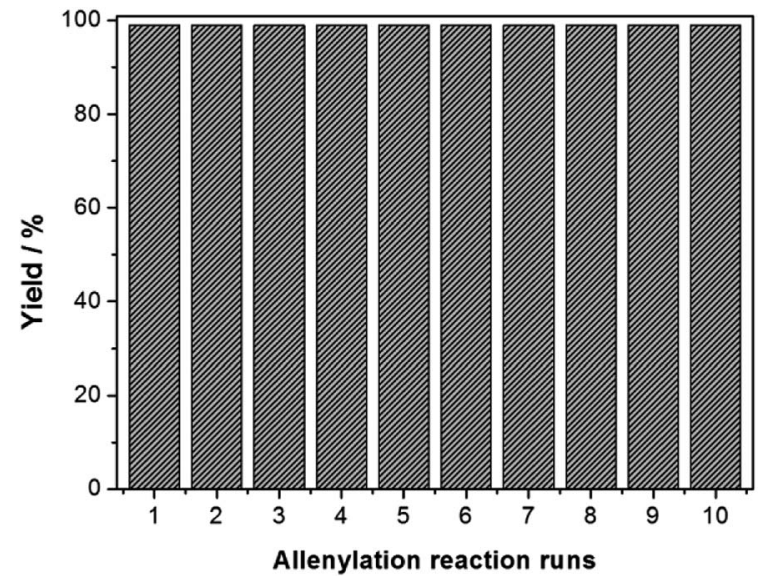

Fig. $5 \mathrm{MIL}-101-\mathrm{SO}_{3} \mathrm{H}$ catalyst recycling test for the allenylation of $1 \mathrm{a}$.

$\mathrm{S} 2 \dagger)$, which also suggested the high chemical stability of the MIL-101- $\mathrm{SO}_{3} \mathrm{H}$ catalyst.

\section{Experimental}

\section{Synthetic procedures}

General procedure for synthesis of MIL-101-SO 3 H. MIL-101 and MIL-101-SO $\mathrm{SO}_{3} \mathrm{H}$ were prepared according to the literature. ${ }^{14,18}$

General procedure for synthesis of propargyl boronates. Modified from the procedure by Brown et al. ${ }^{\mathbf{1 9}}$ (triisopropylsilyl) acetylene ( $5 \mathrm{~g}, 27.5 \mathrm{mmol})$ was added to a solution of LDA (26.3 mmol) in dry THF $(60 \mathrm{~mL})$ previously cooled to $78{ }^{\circ} \mathrm{C}$ under argon and allowed to stir for $1 \mathrm{~h}$. 2-(Iodomethyl)-4,4,5,5tetramethyl-1,3,2-dioxaborolane $(6.7 \mathrm{~g}, 25 \mathrm{mmol})$ was then added in one portion. After an additional $30 \mathrm{~min}$ of stirring, the reaction allowed to warm to room temperature and was left overnight without stirring. The reaction was then cooled to $0{ }^{\circ} \mathrm{C}$ and $2 \mathrm{M}$ anhydrous $\mathrm{HCl}$ in diethyl ether $(13.75 \mathrm{~mL}, 27.5 \mathrm{mmol})$ was added carefully dropwise with vigorous stirring. The

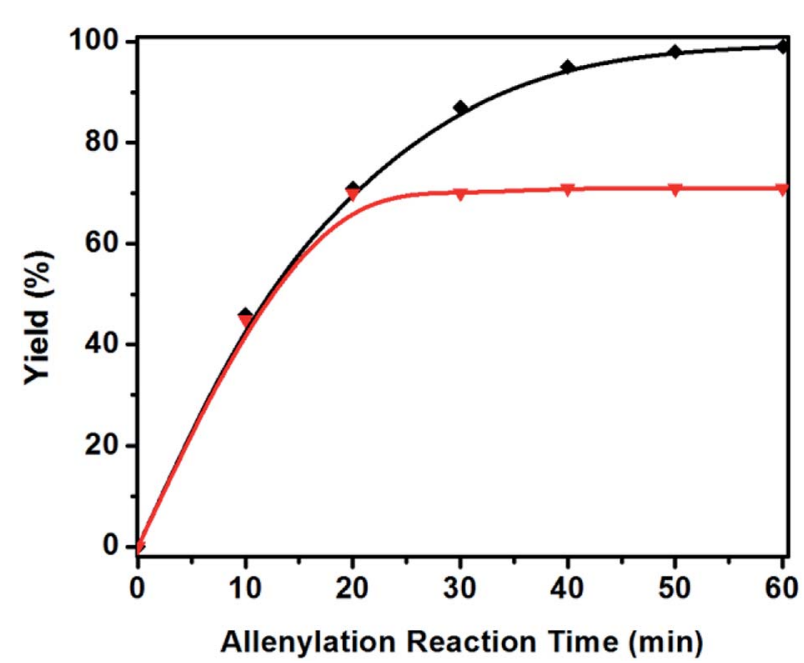

Fig. 6 MIL-101- $\mathrm{SO}_{3} \mathrm{H}$ catalyst hot filtration test. 
precipitate was then filtered off and the solvent removed. The resulting residue was extracted with pentane $(100 \mathrm{~mL}$ for 3 times) and the extracts combined and cooled to $-78{ }^{\circ} \mathrm{C}$ overnight. The pentane solution was warmed to room temperature and then decanted into an oven-dried $500 \mathrm{~mL}$ flask and solvent then removed.

General procedure for synthesis of $\alpha$-allenic alcohols. A $10 \mathrm{~mL}$ round-bottom flask was charged with stir bar under open air. To the flask was added MIL-101-SO ${ }_{3} \mathrm{H}(0.005 \mathrm{mmol}$ based on $-\mathrm{SO}_{3} \mathrm{H}$ group) and propargyl boronate $1 \mathrm{a}(177 \mathrm{mg}, 0.55 \mathrm{mmol})$ then dissolved in $\mathrm{CH}_{2} \mathrm{Cl}_{2}(2 \mathrm{~mL})$. The mixture was stirred at room temperature for 5 minutes. Then benzaldehyde $2 \mathrm{a}(51 \mu \mathrm{L}$, $0.5 \mathrm{mmol}$ ) was added and stirred for $1 \mathrm{~h}$. The organic layer was separated and the aqueous layer extracted with hexanes and the product purified by flash silica gel chromatography (1-5\% acetone in hexanes or 100\% DCM) to afford 3a as a colorless oil.

Reusability of the MIL-101-SO $\mathrm{S}_{3} \mathrm{H}$ catalyst. For the recyclability test of the MIL-101- $\mathrm{SO}_{3} \mathrm{H}$ catalyst, the catalytic reactions were performed under the same optimized conditions in dichloromethane for $1 \mathrm{~h}$ using the recovered MIL-101- $\mathrm{SO}_{3} \mathrm{H}$ catalyst. A leaching study of the MIL-101- $\mathrm{SO}_{3} \mathrm{H}$ catalyst was conducted; the mother liquor was filtered and the supernatant was re-evaluated using fresh starting material under optimized catalytic conditions.

\section{Conclusions}

In conclusion, a heterogeneous $\mathrm{MIL}-101-\mathrm{SO}_{3} \mathrm{H}$ catalyst bearing an aromatic sulfonic acid group was synthesized and applied to allenylation reaction of aldehydes for the efficient synthesis $\alpha$ allenic alcohols. Simple reaction setup using mild reaction conditions and low catalyst loadings are hallmarks of this MOF promoted allenylation methodology. The MIL-101- $\mathrm{SO}_{3} \mathrm{H}$ promoted reaction was found to be general for aldehydes and the ability to vary the alkyne substitution on the boronate, which makes this methodology a powerful tool for the generation of a wide range of $\alpha$-allenic alcohol products. The structural morphology and properties of $\mathrm{MIL}-101-\mathrm{SO}_{3} \mathrm{H}$ were fully characterized by SEM, XRD, TGA, FTIR and BET. The newly developed MIL-101- $\mathrm{SO}_{3} \mathrm{H}$ showed higher reaction efficiency and selectivity in the allenylation reaction at $1 \mathrm{~mol} \%$ catalyst loadings in comparison with several other catalyst systems. The high chemical stability of the MIL-101-SO $\mathrm{S}_{3} \mathrm{H}$ catalyst was due to its strong covalent bond, and did not suffer from leaching. Further studies involving new synthetic applications of the MIL-101$\mathrm{SO}_{3} \mathrm{H}$ catalyst are currently in progress and will be reported in the due course.

\section{Conflicts of interest}

There are no conflicts to declare.

\section{Acknowledgements}

This work is supported by Beijing Natural Science Foundation (No. 2172037) and National Natural Science Foundation of China (No. 51673157). We also thank the Natural Science Basic
Research Plan in Shaanxi Province of China (No. 2018JQ5028, No. 2017JM5134 and No. 2018JM5047) and the Science Research Foundation of Xijing University (Grant No. XJ16T02) for financial support.

\section{Notes and references}

1 J. A. Marshall, B. W. Gung and M. L. Grachan, in Modern Allene Chemistry, ed. N. Krause and A. S. K. Hashmi, WileyVCH, Weinheim, 2004.

2 (a) S. Ma and S. Zhao, J. Am. Chem. Soc., 2001, 123, 5578; (b) N. Krause, A. Hoffmann-Roeder and J. Canisius, Synthesis, 2002, 1759; (c) B. Alcaide, P. Almendros and C. Aragoncillo, Chem.-Eur. J., 2002, 8, 1719; (d) D. Xu, Z. Li and S. Ma, Chem.-Eur. J., 2002, 8, 5012; (e) E. Yoneda, S. Zhang, D. Zhou, K. Onitsuka and S. Takahashi, J. Org. Chem., 2003, 68, 8571; (f) W. Wang, A. Clay, R. Krishnan, N. J. Lajkiewicz, L. E. Brown, J. Sivaguru and J. A. Porco Jr, Angew. Chem., Int. Ed., 2017, 56, 14479; (g) C. Qi, W. Wang, K. D. Reichl, J. McNeely and J. A. Porco Jr, Angew. Chem., Int. Ed., 2018, 57, 2101; (h) S. Liu, W. Wang, L. E. Brown, C. Qiu, N. J. Lajkiewicz, T. Zhao, J. Zhou, J. A. Porco Jr and T. Wang, EBioMedicine, 2015, 11, 1600; (i) W. Wang, R. Cencic, L. Whitesell, J. Pelletier and J. A. Porco Jr, Chem.-Eur. J., 2016, 22, 12006; (j) C. Mukai, I. Nomura and S. Kitagaki, J. Org. Chem., 2003, 68, 1376; (k) A. S. K. Hashima, M. C. Blanco, D. Fischer and J. W. Bats, Eur. J. Org. Chem., 2006, 2006, 1387; (l) H. C. Brown, U. R. Khire and G. Narla, J. Org. Chem., 1995, 60, 8130.

3 (a) A. Hoffmann-Röder and N. Krause, Org. Lett., 2001, 3, 2537; (b) F. Zamani, S. G. Pyne and C. J. T. Hyland, J. Org. Chem., 2017, 82, 6819; (c) R. R. Tata and M. Harmata, Org. Lett., 2016, 18, 5684; (d) B. Yang, C. Zhu, Y. Qiu and J. Bäckvall, Angew. Chem., Int. Ed., 2016, 55, 5568.

4 (a) M. Tomoya, N. Takayuki, B. Tsuneaki and M. Masahiro, Chem. Lett., 2015, 44, 700; (b) H. K. Grover, M. R. Emmett and M. A. Kerr, Org. Biomol. Chem., 2015, 13, 655; (c) H. Hori, S. Arai and A. Nishida, Adv. Synth. Catal., 2017, 359, 1170; (d) M. Yasui, R. Ota, C. Tsukano and Y. Takemoto, Nat. Commun., 2017, 8, 674.

5 R. W. Friesen and M. Blouin, J. Org. Chem., 1993, 58, 1653. 6 (a) R. W. Friesen and A. Giroux, Tetrahedron Lett., 1993, 34, 1867; (b) C. S. Adams, R. D. Grigg and J. M. Schomaker, Chem. Sci., 2014, 5, 3046.

7 R. W. Friesen and A. E. Kolaczewska, J. Org. Chem., 1991, 56, 4888.

8 Y. Huang, J. Liang, X. Wang and R. Cao, Chem. Soc. Rev., 2017, 46, 126.

9 (a) X. Cao, C. Tan, M. Sindoro and H. Zhang, Chem. Soc. Rev., 2017, 46, 2660; (b) Q. Yang, Q. Xu and H. Jiang, Chem. Soc. Rev., 2017, 46, 4774.

10 J. Jiang and O. M. Yaghi, Chem. Rev., 2015, 115, 6966.

11 (a) J. Juan-Alcaniz, R. Gielisse, A. B. Lago, E. V. RamosFernandez, P. Serra-Crespo, T. Devic, N. Guillou, C. Serre, F. Kapteijn and J. Gascon, Catal. Sci. Technol., 2013, 3, 2311; (b) A. Klinkebiel, N. Reimer, M. Lammert, N. Stock and U. Luning, Chem. Commun., 2014, 50, 9306; (c) H. Li, 
K. Wang, D. Feng, Y. Chen, W. Verdegaal and H. Zhou, ChemSusChem, 2016, 9, 2832.

12 H. Li, K. C. Wang, D. W. Feng, Y. P. Chen, W. Verdegaal and H. C. Zhou, ChemSusChem, 2016, 9, 2832.

13 (a) M. B. Boroujeni, A. Hashemzadeh, M. T. Faroughi, A. Shaabani and M. M. Amini, $R S C A d v ., 2016,6,100195$; (b) M. Saikia and L. Saikia, RSC Adv., 2016, 6, 15846.

14 Y. Zhou, Y. Chen, Y. Hu, G. Huang, S. Yu and H. Jiang, Chem.-Eur. J., 2014, 20, 14976.

15 G. Chang, M. Huang, Y. Su, H. Xing, B. Su, Z. Zhang, Q. Yang, Y. Yang, Q. Ren, Z. Bao and B. Chen, Chem. Commun., 2015, 51, 2859.

16 (a) Y. Luan, Y. Qi, H. Gao, R. S. Andriamitantsoa, N. Zheng and G. Wang, J. Mater. Chem. A, 2015, 3, 17320; (b) X. Du,
X. Li, H. Tang, W. Wang, D. Ramella and Y. Luan, New J. Chem., 2018, 42, 12722.

17 (a) Y. Luan, N. Zheng, Y. Qi, J. Yu and G. Wang, Eur. J. Inorg. Chem., 2014, 2014, 4268; (b) J. Zhao, W. Wang, H. Tang, D. Ramella and Y. Luan, Mol. Catal., 2018, 456, 57; (c) Y. Qi, Y. Luan, J. Xu, X. Peng and G. Wang, Chem.-Eur. J., 2014, 20, 1-10.

18 (a) G. Akiyama, R. Matsuda, H. Sato, M. Takata and S. Kitagawa, Adv. Mater., 2011, 23, 3294; (b) G. Ferey, C. Mellot-Draznieks, C. Serre, F. Millange, J. Dutour, S. Surble and I. Margiolaki, Science, 2005, 309, 2040.

19 H. C. Brown, C. D. Roy and R. Soundararajan, Tetrahedron Lett., 1997, 38, 765. 